\title{
LARGE FRONTOETHMOIDAL MUCOCOELE- A CASE REPORT
}

\author{
Puneet Kaur ${ }^{1}$, Jagdeepak Singh², Kulwinder Singh Sandhu3 ${ }^{3}$ Rajneet Kaur ${ }^{4}$
}

1 Junior Resident, Department of Otorhinolaryngology, Ram Lal Eye and ENT Hospital, Government Medical College, Amritsar, Punjab. ${ }^{2}$ Professor and HOD, Department of Otorhinolaryngology, Ram Lal Eye and ENT Hospital, Government Medical College, Amritsar, Punjab.

${ }^{3}$ Assistant Professor, Department of Otorhinolaryngology, Ram Lal Eye and ENT Hospital, Government Medical College, Amritsar, Punjab.

${ }^{4}$ Senior Resident, Department of Otorhinolaryngology, Ram Lal Eye and ENT Hospital, Government Medical College, Amritsar, Punjab.

HOW TO CITE THIS ARTICLE: Kaur P, Singh J, Sandhu KS, et al. Large frontoethmoidal mucocoele- a case report. J. Evolution Med. Dent. Sci. 2018;7(20):2519-2521, DOI: 10.14260/jemds/2018/566

\section{PRESENTATION OF CASE}

Mucocoeles of the paranasal sinuses were first described by Langenbeck (1820) under the name of hydatides. ${ }^{1}$ Rollet (1909) suggested the name mucocoele. They have expansile nature with slow growth and may eventually compress important neighbouring structures such as orbit and intracranial cavity. ${ }^{2}$ On histopathology, they are cyst-like structures lined with respiratory epithelium and filled with mucus. Patients with mucocoeles in the frontoethmoidal region are referred to ophthalmic surgeons in the first instance due to orbital displacement. The orbital symptoms include proptosis, lateral displacement, inferior displacement, diplopia, limited ocular mobility and decreased visual acuity. The patients may also complain of facial pain and headache.

\section{a. History}

A 50-year-old male presented to ENT OPD of Govt. Medical College, Amritsar with history of outward and downward displacement of left eye for 4 months (Fig. 1). The patient also complained of headache on the left side of forehead. No history of diplopia or decreased vision was given by the patient. There was no history of trauma to the site. There was no history of nasal discharge or nasal obstruction.

\section{b. On Examination}

The left eye showed mild congestion of the bulbar conjunctiva. Proptosis was noted. Inferior and lateral displacement of the eyeball was seen. Visual acuity was 6/9 in the right eye and 6/36 in the left eye. Extraocular movements were restricted in the superior and medial directions on left side. Pupillary reactions to light and accommodation were normal in both eyes. Fundus examination was normal in both eyes. No swelling on the forehead was noted. On anterior rhinoscopy, nose was normal.

\section{c. Investigations}

Blood investigations including CBC, RBS, RFT, LFT, viral markers were normal. X-ray PNS showed downward scalloping of superior orbital margin and expansion of left frontal sinus. Left maxillary sinus was hazy. CT scan (Fig. 2) showed expansion of left frontal sinus with breach in the posterior wall and floor of left frontal sinus with evidence of retained secretions within the expanded sinus.

'Financial or Other Competing Interest': None.

Submission 26-03-2018, Peer Review 01-05-2018,

Acceptance 07-05-2018, Published 14-05-2018.

Corresponding Author:

Dr. Puneet Kaur,

Junior Resident

Department of Otorhinolaryngology, Ram Lal Eye and ENT Hospital,

Government Medical College, Amritsar, Punjab.

E-mail: puneetkaur89@ymail.com

DOI: $10.14260 /$ jemds $/ 2018 / 566$

\section{(c) $(1) \odot$}

The lesion was extending in left orbit abutting the superior rectus and superior oblique muscle causing its indentation. There was evidence of intracranial extradural extension of lesion causing indentation of left frontal lobe. MRI showed large, well-defined cystic lesion arising from the left frontal sinus measuring about $46 \times 36 \times 33 \mathrm{~mm}$ in maximum dimensions with fluid levels within it. Inferiorly, it was displacing and compressing roof of left orbit leading to proptosis of left eye. Posteriorly, it was bulging into the anterior cranial fossa and compressing the left frontal lobe of brain.

\section{DIFFERENTIAL DIAGNOSIS}

\section{The Possible differential Diagnosis are-}

1. Encephalocoeles.

2. Cholesterol granuloma.

3. Epidermoid cyst.

4. Meningioma.

5. Neurofibroma.

6. Paraganglioma.

\section{CLINICAL DIAGNOSIS}

The clinical diagnosis of the case after all the relevant investigations was frontal mucocoele, left side.

\section{DISCUSSION OF MANAGEMENT}

Under general anaesthesia, endoscopic frontal recess surgery was performed with intact bulla technique. Uncinectomy was done. The agger nasi cells were de-roofed using Kerrison's punch and frontal recess area was explored. All anterior region cell septae were broken. Bluish point was seen at the narrow middle part of the frontal hour glass recess. This was presumed to be the cyst wall and was incised using cruciate incision. Pulsatile clear watery fluid came out and immediately per operative the eyeball regained its original position. Trephination was done to check for the intactness of dura. Frontal sinus was visualised, which was empty. Posterior table of frontal sinus was eroded. Upon insertion of the endoscope, the eyeball was seen to twitch superiorly indicative of erosion of roof of orbit. After being sure about our incision having been placed in cyst wall and dura being intact, the area of incision was widened transnasally using No. 3 diamond burr.

Post-operatively, there was no episode of CSF leak and wound healing was normal. The patient was instructed not to blow the nose, keep head raised, get treatment for constipation if required and to quit smoking. The postoperative picture of the patient is as shown in Fig. 3. 


\section{DIAGNOSTIC DISCUSSION}

After co-relating the pre-operative radiological finding with the intra-operative surgical finding, it was confirmed to be a case of frontal mucocoele.

\section{FINAL DIAGNOSIS}

The final diagnosis of the case was that of a large frontal mucocoele on left side eroding the posterior table and floor of the sinus (Roof of the orbit).

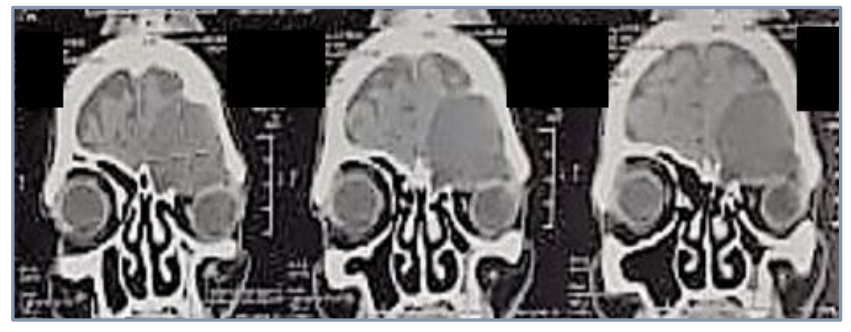

Figure 1

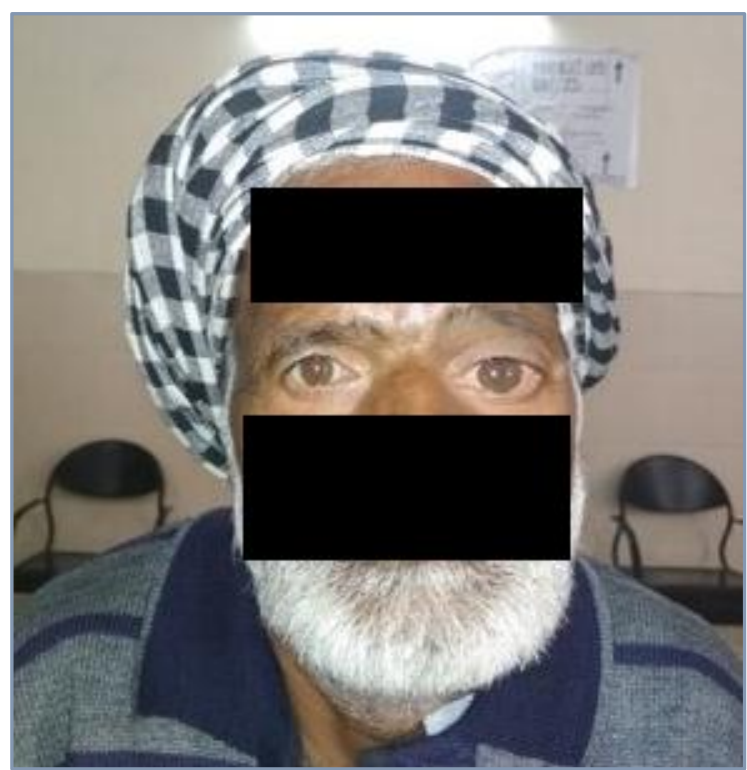

Figure 2

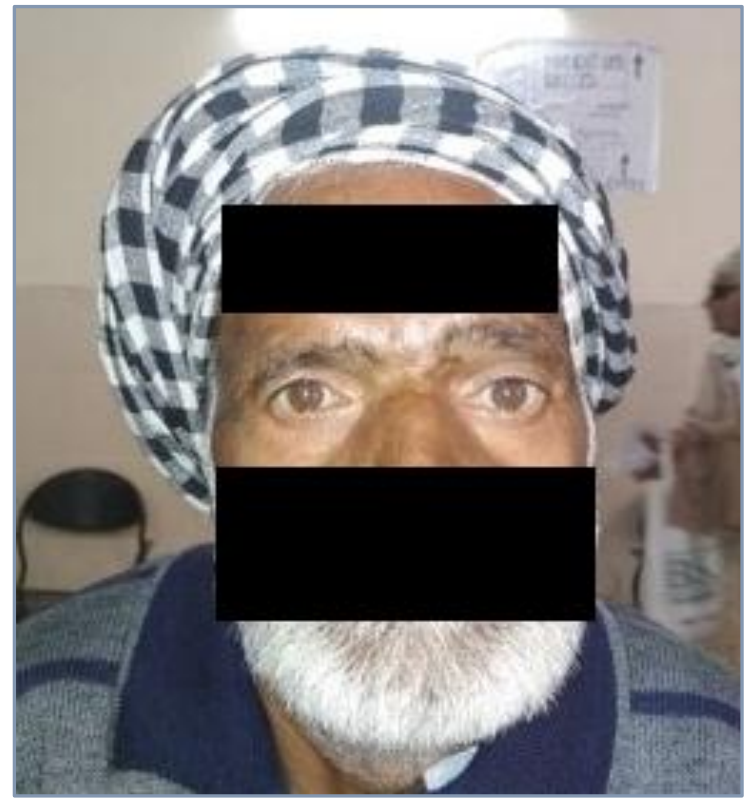

Figure 3

\section{DISCUSSION}

Mucocoele is a cystic lesion of the epithelial recover layer that affects the paranasal sinuses, contains thick mucus inside, has slow growth and expansive characteristics. ${ }^{2,3}$ Its aetiology has not been fully defined yet, but it is believed that it is caused by obstruction of drainage ostium of affected paranasal sinus owing to chronic processes of rhinosinusitis (infectious or allergic), nasosinusal polyposis, craniofacial trauma, previous surgery, benign tumours (osteomas, bone fibrous dysplasia) or malignant neoplasms (primary or metastatic).3,4

Approximately, $60-89 \%$ occur in the frontal sinus, followed by $8-30 \%$ in the ethmoidal sinuses and less than $5 \%$ in the maxillary sinus. Sphenoid sinus mucocoeles are rare. ${ }^{5}$ Mucocoeles can form at any age, but the majority are diagnosed in patients of 40 to 60 years old. 5 Males and females are equally affected.

Mucocoeles tends to expand, remodel and reabsorb bone walls of affected paranasal sinus, changing their integrity and occasionally affecting the neighbouring structures such as the orbit and intracranial cavity.2,6 Pathophysiology of the mechanism of bone reabsorption produced by mucocoeles is still obscure. It is believed that osteolysis is produced by reduction of vascularisation of the bone due to the mechanism of compression and/ or by the action of inflammatory mediators abundantly present in the mucous of this affection such as cytokines (IL1, IL6), vascular adhesion molecules and prostaglandins. ${ }^{6}$

The clinical presentation of mucocoeles varies with their anatomical site. The onset of symptoms is usually insidious. Patients with frontoethmoidal mucocoeles may develop frontal headache, facial asymmetry or swelling as well as ophthalmological manifestations such as impaired visual acuity, reduced ocular mobility or proptosis. Clinical presentation of the mucocoeles varies from asymptomatic to incapacitating headache and visual disturbance. 7,8 Proptosis $(83 \%)$ and diplopia (45\%) are the most common complaints. ${ }^{7}$

The diagnosis is based on imaging exams. ${ }^{9}$ Even though simple $\mathrm{x}$-ray may show opacification, bone erosion or expansion of mucocoeles, CT scan is the preferred exam because it evidences bone involvement, assesses intracranial and/or orbital extension and supports surgical planning.

Treatment of mucocoeles is surgical and the access routes may be either external or endonasal.10,11,12,13 External approach is made through frontoethmoidectomy (Lynch's procedure) or by osteoplastic flaps with or without frontal sinus obliteration and total excision of mucosa.11,14 For many years, these techniques were the only surgical alternative to treat frontoethmoidal mucocoeles. They are aggressive procedures with high morbidity and currently they are reserved for extreme cases with significant intracranial or orbital extension.2,3 The current tendency is to conduct functional, little invasive and low morbidity procedure with nasosinusal endoscopic surgery with marsupialisation and abundant drainage of the lesion, preserving the epithelium.2,3,11,15

\section{CONCLUSION}

Mucocoeles are benign lesions of expansive characteristic that may cause severe complications at orbital and intracranial levels and for this reason they should be diagnosed and treated early. Here, we present a case of frontal mucocoele causing orbital symptoms and was hence 
surgically managed. Three months post-operative follow-up has not revealed any recurrence of the symptoms. Marsupialisation with drainage through nasosinusal approach proves to be a safe and efficient procedure in therapeutic approaches to frontoethmoidal mucocoeles.

\section{REFERENCES}

[1] Alberti PW, Marshall HF, Black MJI. Fronto-ethmoidal mucocele as a cause of unilateral proptosis. $\mathrm{Br} \mathrm{J}$ Ophthalmol 1968;52(11):833-8.

[2] Hurley DB, Javer AR, Kuhn FA, et al. The endoscopic management of chronic frontal sinusitis associated with frontal sinus posterior table erosion. Am J Rhinol 2000;14(2):113-20.

[3] Chiarini L, Nocini PF, Bedogni A, et al. Intracranial spread of a giant frontal mucocele: case report. British Journal of Oral \& Maxillofacial Sugery 2000;38(6):63740.

[4] Lloyd G, Lund VJ, Savy L, et al. Radiology in focus. The Journal of Laryngology and Otology 2000;114:233-6.

[5] Arrue P, Kany MT, Serrano E, et al. Mucoceles of the paranasal sinuses: uncommon location. J Laryngol Otol 1998;112(9):840-4.

[6] Lund VJ, Henderson B, Song Y. Involvement of cytokines and vascular adhesion receptors in the pathology of fronto-ethmoidal mucoceles. Acta Otolaryngol 1993;113(4):540-6.

[7] Tan CS, Yong VK, Yip LW, et al. An unusual presentation of a giant frontal sinus mucocele manifesting with a subcutaneous forehead mass. Ann Acad Med Singapore 2005;34(5):397-8.
[8] Edelman RR, Hesselink JR, Zlatkin MB, et al. Clinical magnetic resonance imaging. $3^{\text {rd }}$ edn. Philadelphia: Elsevier 2006: p. 2035-7.

[9] Lund VJ, Rolfe ME. Ophthalmic considerations in fronto-ethmoidal mucococeles. J Laryngol Otol 1989;103(7):667-9.

[10] Rubin JS, Lund VJ, Salmon B. Frontoethmoidectomy in the treatment of mucococeles. A neglected operation. Arch Otolalaryngol Head Neck Surg 1986;112(4):4346.

[11] Ulualp SO, Carlson TK, Toohill RJ. Osteoplastic flap versus modified endoscopic Lothrop procedure in patients with frontal sinus disease. Am J Rhinology 2000;14(1):21-6.

[12] Busaba NY, Kieff D. Endoscopic sinus surgery for inflammatory maxillary sinus disease. The Laryngoscope 2002;112(8 Pt 1):1378-83.

[13] Gady H. Endoscopic management of 108 sinus mucoceles. The Laryngoscope 2001;111(12):2131-4.

[14] Benninger MS, Marks S. The endoscopic management of sphenoid and ethmoidmucoceles with orbital and intranasal extension. Rhinology 1995;33(3):157-61.

[15] Busaba NY, Salman SD. Maxillary sinus mucoceles: clinical presentation and long-term results of endoscopic surgical treatment. The Laryngoscope 1999;109(9):1446-9. 